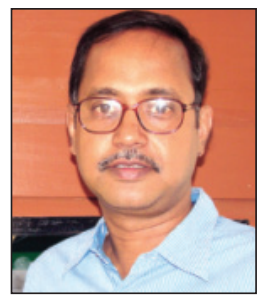

INDIAN JOURNAL OF POWER \& RIVER VALLEY DEVELOPMENT www.ijprvd.info

Jayanta Bhattacharya

Chief Editor

\title{
The mind of a hybrid car buyer
}

Car buyers are increasingly being encouraged to adopt cleaner, more eco-friendly behaviours. However, hybrid car adoption remains low, which impedes the move towards a lower carbon economy. Five types of concerns and risk cloud their minds: social, psychological, time, financial, and network externalities, and three comparative product factors drive final purchase: advantages, attractiveness, and superiority.

The plug in electric vehicles $\left(\mathrm{PEVs}^{1}\right)$ and hybrid electric vehicles (HEVs) can play an important role in the move towards decarbonizing the transportation sector, as they possess technology which can reduce greenhouse gases and pollution. The production concentrated on PEVs including plug in hybrids (HEVs) that can be powered by gasoline or grid electric as well as "pure" electric vehicles that use grid electricity only. HEVs can also work on gasoline, do not require plugging into an electric grid for refuelling. As such, HEVs may provide solutions to many factors that act as barriers today to adopting PEVs including a lack of public electrical charging points, range anxiety and poor battery life with high replacement costs. Therefore, as of now, HEVs may be more practical to adopt than PEVs.

While the mind of a car buyer is largely influenced by the following:

1. The highly educated, generally a post graduate and resourceful persons, assured as they are, are more ready to embrace $\mathrm{HEVs}$ as against gasoline cars because they understand climate change challenges and would love to make a statement.

2. Government policy will encourage decision making and must be visible in the purse. Transnational policies such as directly incentivizing the buyers for their choice and use can help the progress. For example, tradable emission reduction payments or discounts for the choice and use of HEVs in a trading market

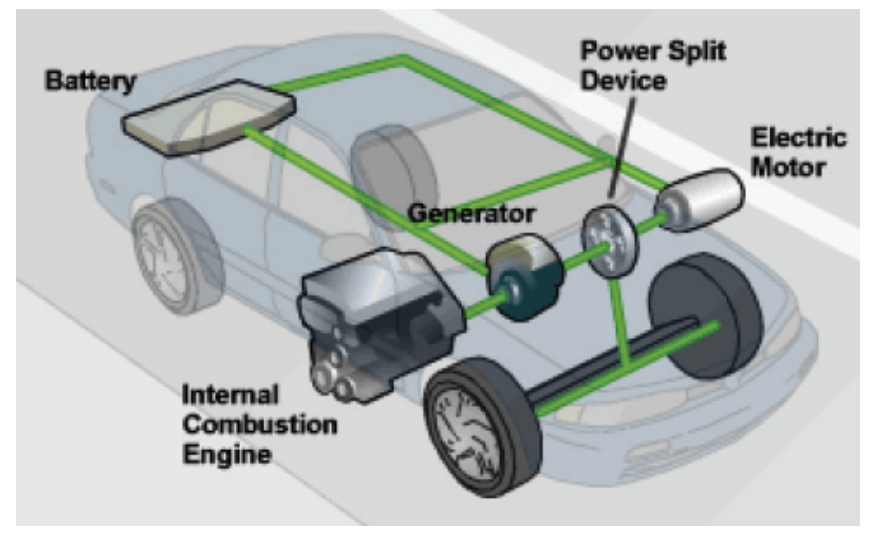

The construction of a hybrid electric vehicle

structure can help adoption.

3. HEV uptake remains low because the buyers do not see translatable benefits; continued government support and funding is necessary for programmes that stimulate innovation, drive technological developments that stimulate product related improvements and reduce perceived risks (e.g. by enhancing battery storage and longevity).

4. Informational campaigns and other forms of education should continue to be developed, to enhance consumer's awareness and stimulate adoption. For example, a comparison of gaseous pollution discharges by both gasoline vehicles and HEVs can prepare the consumer mind.

5. Visibility and presence by the sides of the roads of charging and repairing/substituting stations across all states will assure the buyer that they would not be in the lurch if the vehicle fails. 